\title{
The influence of observed and modelled net longwave radiation on the rate of estimated potential evapotranspiration
}

\author{
Jitka Kofroňová ${ }^{1,2 *}$, Miroslav Tesař ${ }^{1}$, Václav Š́pek ${ }^{1}$ \\ 1 The Institute of Hydrodynamics of the Czech Academy of Sciences, Pod Pat'ankou 30/5, Prague, 166 12, Czech Republic. \\ 2 Department of Physical Geography and Geoecology, Faculty of Science, Charles University in Prague, Albertov 6, Prague, 128 43, Czech \\ Republic. \\ * Corresponding author. E-mail: kofronova@ih.cas.cz
}

\begin{abstract}
Longwave radiation, as part of the radiation balance, is one of the factors needed to estimate potential evapotranspiration (PET). Since the longwave radiation balance is rarely measured, many computational methods have been designed. In this study, we report on the difference between the observed longwave radiation balance and modelling results obtained using the two main procedures outlined in FAO24 (relying on the measured sunshine duration) and FAO56 (based on the measured solar radiation) manuals. The performance of these equations was evaluated in the April-October period over eight years at the Liz experimental catchment and grass surface in the Bohemian Forest (Czech Republic). The coefficients of both methods, which describe the influence of cloudiness factor and atmospheric emissivity of the air, were calibrated. The Penman-Monteith method was used to calculate the PET. The use of default coefficient values gave errors of 40-100 $\mathrm{mm}$ (FAO56) and 0-20 mm (FAO24) for the seasonal PET estimates (the PET was usually overestimated). Parameter calibration decreased the FAO56 error to less than 20 mm per season (FAO24 remained unaffected by the calibration). The FAO56 approach with calibrated coefficients proved to be more suitable for estimation of the longwave radiation balance.
\end{abstract}

Keywords: Radiation balance; Longwave radiation; Potential evapotranspiration; Penman-Monteith; Calibration.

\section{INTRODUCTION}

Evapotranspiration is one of the main fluxes in the global water cycle and is the dominant controlling factor of climate and hydrology at the local and global scales. In terms of quantity, it is the second most dominant process (after precipitation) of dry land hydrology, accounting for approximately $65 \%$ of the precipitation returning to the atmosphere (Shi et al., 2008). It affects agricultural water use, ecosystem functioning and aridity/humidity conditions. It is also a fundamental factor controlling energy and mass exchange between terrestrial ecosystems and the atmosphere (Fischer et al., 2005).

The overall process of evapotranspiration is determined by two main factors: firstly by the amount of available energy, and secondly by the amount of available water. Potential evapotranspiration (PET) represents its maximum rate under conditions of sufficient water supplies. Hence, PET is primarily affected by weather parameters and surface characteristics (Allen et al. 1998, Yin et al., 2008). Several equations for the estimation of PET have been designed, each of which corresponds to sitespecific conditions. In general, three distinct approaches can be identified: aerodynamic (Dalton, 1802), energy balance (Pristley and Taylor, 1972) and a combined approach (Penman, 1948). The energy necessary for the process of evapotranspiration is primarily represented by incoming shortwave solar radiation. The significant effect of longwave radiation (emitted mainly by the Earth and the atmosphere) on the total radiation balance has also been documented (e.g. by Duarte et al., 2006; Kjaersgaard et al., 2009; Temesgen et al., 2007). The longwave radiation serves as a cooling mechanism for the Earth's surface and hence reduces the available energy for the evaporation. Nevertheless, studies quantifying the influence of the net longwave radiation balance on the PET values are sparse (e.g. Yin et al., 2008). Net radiation (Rn) is an elementary variable used in several methods of PET estimation based on the energy balance, and represents the difference between the total incoming and outgoing radiation fluxes, i.e. net shortwave radiation (Rns) and net longwave radiation (Rnl) (Allen et al., 1998; Irmak et al., 2010). Rns is typically measured using pyranometers, and is readily available at numerous meteorological stations. However, measurements of Rnl are limited due to technical and economic factors (Carmona et al., 2017; Irmak et al., 2010; Temesgen et al., 2007). Radiation formulas from FAO56 (Allen et al., 1998, RnlFa056) and FAO24 (Doorenbos and Pruitt, 1977, RnlFAO24) are therefore often used to estimate this quantity. The Rnl FAO56 $_{6}$ equation is based on the ratio of the observed to the maximum possible incoming shortwave radiation, while the RnlFaO24 equation is based on the ratio of the actual duration of sunshine to the maximum possible duration of daylight hours. Since the data of actual duration of sunshine for RnlFAO24 is often unavailable, the FAO56 method serves as a basis for the estimation of Rnl (Kjaersgaard et al., 2009). However, these formulas cannot be used universally, meaning that a comparison with site-specific conditions is necessary (Matsui and Osawa, 2015). They contain several coefficients recommended by Allen et al. (1998) that originate in local calibration based on site-specific conditions. Multiple authors reported that different empirical coefficients work better for model-based representations in different locations (Arellano et al., 2016; Carmona et al., 2017; Irmak et al., 2003a; Kjaersgaard et al., 2007b; Yin et al., 2008). The reason is that besides the surface temperature the longwave radiation (both outgoing and incoming) is influenced by local conditions, e.g. by soil type, structure of vegetation, influence of nearby high trees or buildings, concentration of $\mathrm{CO}_{2}$ and water vapour, and the presence of clouds and dust particles in the atmosphere (Allen et al., 1998). However, only some of these factors are taken into account in the above mentioned equations (cloudiness factor and atmospheric emissivity). The variability in the remaining ones is the main reason why the site-specific coefficient values are neces- 
sary. The modelled values of RnlFaOs6 using the default coefficients have been observed to be generally less negative than the measured values. This concerns e.g. humid (Yin et al., 2008), sub-humid and semiarid places (Irmak et al., 2010). The variability of RnlFAO56 parameters may result in incorrectly estimated PET in hydrological studies. The reason for that is the insufficient reduction of a positive short wave energy balance. Hence, higher PET values can then be observed as more energy is available (compared to a measured energy balance). The influence of inaccurately estimated Rnl on the rate of PET is still poorly examined (Irmak et al., 2003b; Yin et al., 2008).

The aims of this study are therefore: (i) to compare the values of Rnl estimated by the FAO56 (Allen et al., 1998) and FAO24 (Doorenbos and Pruitt, 1977) approaches with observed values based on a dataset covering eight years; (ii) to calibrate the coefficients used in RnlFaO56 and RnlFaO24 longwave radiation equations for an experimental site in the Bohemian Forest; and (iii) to investigate the influence of the chosen Rnl estimation approach on the rate of PET calculated by a PenmanMonteith equations (Monteith, 1965).

\section{DATA AND METHODS}

\section{Site description and instrumentation}

The data for this study were obtained in an area of the Liz experimental catchment $\left(49^{\circ} 04^{\prime} \mathrm{N}, 13^{\circ} 41^{\prime} \mathrm{E}\right)$. It is located in a forested, mountainous region that serves as a headwater area for numerous flood events in the Czech Republic. The altitude of the catchment extends from a minimum of 828 m.a.s.l. to a maximum of 1074 m.a.s.l. Using the Köppen climate classification, the site lies in the Dfb zone, which is characterised by a humid continental climate with an approximately uniform precipitation distribution and warm summers. More information about the experimental site can be found e.g. in Votrubová et al. (2017).

All meteorological variables necessary for the modelling were measured at 15-minute (2010-2015) and 10-minute intervals (2016-2017) at the automatic meteorological station located at 830 m.a.s.l (Fig. 1). The necessary datasets contain air temperature (Vaisala HMP45, Finland), relative air humidity (Vaisala HMP45, Finland), wind speed (Vaisala WAA151, Finland), atmospheric pressure (Vaisala PTB110, Finland), and actual duration of sunshine (Meteoservis SD5, CZE). Radiation balance was measured using a CNR1 instrument consisting of two pyranometers CM3 (measuring incoming and outgoing shortwave radiation) and two pyrgeometers CG3 (used for incoming and outgoing longwave radiation) (Kipp \& Zonen, Netherlands). Radiation data are available only for the vegetation season (April-October), since in the winter the sensors may be covered by snow. In the meteorological station the short grass canopy is grown, but it is surrounded by high trees and forest is in the neighbourhood ( 50 meters from the fence).

\section{Experimental methods}

Radiation balance (Rn)

The values of net longwave radiation were calculated using the FAO56 or FAO24 approaches and they were compared with the measured ones obtained from the pyrgeometers.

Net radiation, which is often used in PET equations, is defined as:

$$
R n=R n s-R n l=\left(S W_{\downarrow}-S W_{\uparrow}\right)+\left(L W_{\downarrow}-L W_{\uparrow}\right)
$$

where the net radiation $R n\left[\mathrm{MJ} \mathrm{m}^{-2} \mathrm{~d}^{-1}\right]$ is the numerical differ-

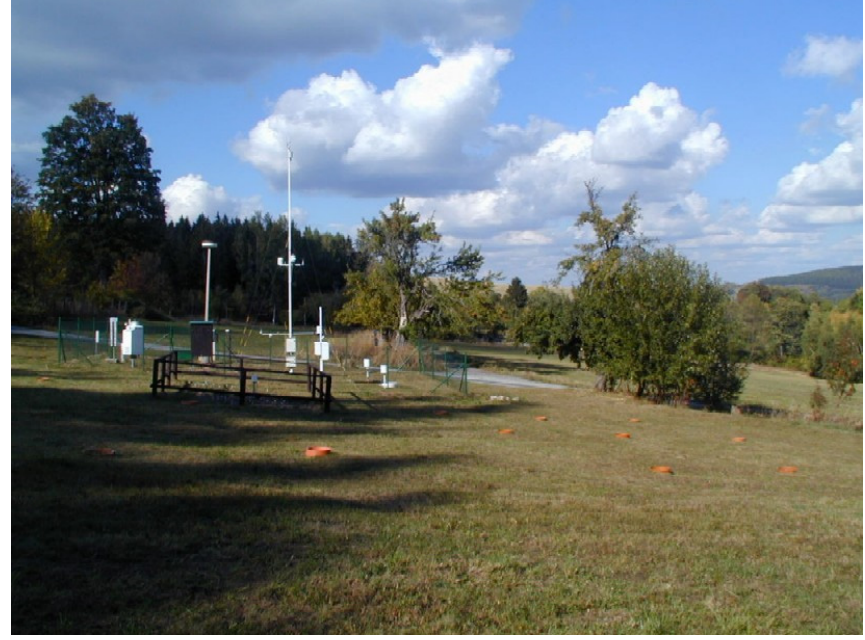

Fig. 1. Meteorological station surroundings.

ence between the net shortwave radiation $R n s\left[\mathrm{MJ} \mathrm{m}^{-2} \mathrm{~d}^{-1}\right]$ and the net longwave radiation $R n l\left[\mathrm{MJ} \mathrm{m}^{-2} \mathrm{~d}^{-1}\right]$. The net short- and longwave radiation (Rns and Rnl, respectively) represent the difference between their incoming $\left(\mathrm{SW}_{\downarrow}, \mathrm{LW}_{\downarrow}\right)$ and outgoing components $\left(\mathrm{SW}_{\uparrow}, \mathrm{LW}_{\uparrow}\right)$. The general equation for the estimation of Rnl by FAO56 manual (Allen et al., 1998) originates from the Stefan-Boltzmann law, and can be described as:

$R n l=\sigma\left[\frac{T_{M A X(K)^{4}+T_{M I N(K)}^{4}}^{4}}{2}\right] \cdot\left(a_{1}-a_{2} \sqrt{e_{a}}\right) \cdot\left(b_{1} \cdot \frac{R_{s}}{R_{s o}}-b_{2}\right)$

Net longwave radiation with coefficients determined in the FAO56 (Allen et al., 1998) approach is given by:

$R n l=$

$\sigma\left[\frac{T_{M A X(K)}{ }^{4}+T_{M I N(K)}{ }^{4}}{2}\right] \cdot\left(0.34-0.14 \sqrt{e_{a}}\right) \cdot\left(1.35 \cdot \frac{R_{s}}{R_{s o}}-0.35\right)$

where $\sigma$ is the Stefan-Boltzmann constant $\left[4,895^{*} 10^{-9} \mathrm{MJ} \mathrm{m}^{-2}\right.$ $\left.\mathrm{d}^{-1} \mathrm{~K}^{-4}\right], T_{M A X}$ and $T_{M I N}$ are the maximum and the minimum air temperature $[\mathrm{K}], e_{a}$ is the actual vapour pressure $[\mathrm{kPa}], R_{s}$ is the total incoming shortwave solar radiation $\left[\mathrm{MJ} \mathrm{m}^{-2} \mathrm{~d}^{-1}\right]$ and $R_{s o}$ is the calculated clear-sky solar radiation $\left[\mathrm{MJ} \mathrm{m}^{-2} \mathrm{~d}^{-1}\right]$. The values $a_{1}=0.34, a_{2}=-0.14, b_{1}=1.35$ and $b_{2}=0.35$ are coefficients recommended by the FAO56 manual that can be modified according to the specific region.

Clear-sky solar radiation can be expressed as:

$R_{s o}=\left(c_{1}+c_{2} \cdot z\right) R_{a}$

where $c_{1}$ and $c_{2}$ are coefficients, $z$ station elevation above sea level [m], and $R_{a}$ is the extraterrestrial radiation $\left[\mathrm{MJ} \mathrm{m}^{-2} \mathrm{~d}^{-1}\right.$ ]. Using the methodology in FAO56, the coefficients are defined as $c_{1}=0.75$ and $c_{2}=0.00002$.

The general methodology in FAO24 (Doorenbos and Pruitt, 1977) for calculating $\mathrm{Rnl}$ is given by the equation:

$R n l=\left(\sigma T_{K}^{4}\right) \cdot\left(a_{1}-a_{2} \sqrt{e_{a}}\right) \cdot\left(b_{1}+b_{2} \frac{n}{N}\right)$

In the RnlFAO24 approach, this equation is used in the following form: 


$$
R n l=\left(\sigma T_{K}^{4}\right) \cdot\left(0.34-0.044 \sqrt{e_{a}}\right) \cdot\left(0.1+0.9 \frac{n}{N}\right)
$$

where $T_{K}$ is the daily mean air temperature $[\mathrm{K}], e_{a}$ is the actual vapour pressure [kPa], $n$ is the actual duration of sunshine [hrs] and $N$ is the number of daylight hours [hrs]. Default values for the coefficients introduced in the FAO24 paper are therefore $a_{1}$ $=0.34, a_{2}=0.044, b_{1}=0.1$ and $b_{2}=0.9$.

\section{Sensitivity analyses and model calibration}

The site specific calibration of the Rnl model coefficients is one of the primary aims of the article. Prior to the calibration the sensitivity analyses (SA) was conducted in order to investigate the influence of particular coefficients on the model performance. The simplest type of SA that varies the input factors (e.g. model coefficients) of the simulation model from their nominal values one at a time (OAT) was used (Pianosi et al., 2016). The procedure was based on changing one parameter at a time and the remaining ones were kept fixed. The sensitivity of the output to the changes in the input factors was observed by calculating the rate of change of the objective function (RMSE in our case). Based on the SA the calibration of model coefficients was done using the genetic algorithm. All the chosen parameters were calibrated simultaneously.

\section{Potential evapotranspiration (PET)}

The influence of Rnl on the rate of PET was determined by three different approaches. First, the observed radiation balance was used. Second, the $\mathrm{Rnl}_{\mathrm{FAO} 56} / \mathrm{Rnl}_{\mathrm{FAO} 24}$ equations were used using a default parameters setup. Finally, the calibrated Rnl models coefficients (based on local conditions) were utilized. Potential evapotranspiration was estimated by PenmanMonteith (Monteith, 1965, Eq. 7). Besides the air temperature, wind speed and vapour pressure, the net radiation (Rnl respectively) represents one of the fundamental inputs of this method.

$$
\lambda P E T=\frac{\Delta(R n-G)+\rho \cdot c\left(e_{s}-e_{a}\right) / r_{a}}{\Delta+\gamma\left(1+\frac{r_{s}}{r_{a}}\right)}
$$

where $\Delta$ describes the slope of the saturation vapour pressure versus air temperature curve $\left[\mathrm{kPa}^{\circ} \mathrm{C}^{-1}\right], R n$ is the net radiation [MJ m $\mathrm{m}^{-2} \mathrm{~d}^{-1}$ ], $G$ is the soil heat flux, $\gamma$ is the psychrometric constant $\left[\mathrm{kPa}{ }^{\circ} \mathrm{C}^{-1}\right], e_{s}-e_{a}$ is the expression of vapour pressure deficit $[\mathrm{kPa}]\left(e_{s}\right.$ is the saturation vapour pressure and $e_{a}$ is the actual vapour pressure), $\lambda$ is the latent heat of vaporisation $[\mathrm{MJ}$ $\left.\mathrm{kg}^{-1}\right], \rho$ is the water density $\left[1000 \mathrm{~kg} \mathrm{~L}^{-1}\right], r_{s} / r_{a}$ is the ratio of surface and aerodynamic resistance $\left[\mathrm{s} \mathrm{m}^{-1}\right]$. Soil heat flux is neglected in this study as it deals with daily average sums of radiation.

\section{Statistical analysis}

The results of the RnlFAO56 and RnlFAO24 formulas (and related different values of PET) were compared with the measured Rnl under different conditions. Total daily, monthly and seasonal average values of Rnl and PET were evaluated. Two error statistics were selected: root mean-square error (RMSE, Eq. 8) and BIAS (Eq. 9). The RMSE involves the square of the difference between the observed and estimated values. Hence, it tends to emphasise larger values of the error in time-series, while lower values are virtually neglected. The BIAS is the average absolute difference between the observed and estimated values, indicating the magnitude and direction (positive/negative) of each error. The smaller the values of RMSE/BIAS, the more precise are the results. These values are defined as:

$$
R M S E=\sqrt{\frac{1}{n} \sum_{i=1}^{n}\left(y_{i}-x_{i}\right)^{2}}
$$

$$
B I A S=\frac{1}{n} \sum_{i=1}^{n}\left(y_{i}-x_{i}\right)
$$

where $y_{i}$ represents the modelled values on the day $i, x_{i}$ the observed values on the day $i$, and $n$ is the number of the sample.

For the trend analyses, the Mann-Kendall (MK) test (Kendall, 1938; Mann, 1945) was originally developed. However, the MK test is sensitive to the presence of autocorrelation in the analysed datasets. In the case of a positive lag-one autocorrelation coefficient (which exists in several hydro-meteorological variables), the MK test may falsely detect a trend as the same ordering of data is supported. We therefore used a modification of the MK test, referred to as the trend-free pre-whitening (TFPW-MK) approach, which was originally designed for positively auto-correlated series (Yue et al., 2002). All tests were performed at a significance level of 5\% using the daily values of particular variables.

\section{RESULTS}

\section{Climate characteristics}

The climatic characteristics of the eight years under evaluation (2010-2017) are illustrated in Figure 2. For each year, only the warmer months (April-October) were used, as measurements of longwave radiation are not available in winter. The long-term average daily air temperature was $6.66^{\circ} \mathrm{C}$ and the average annual sum of precipitation was $851 \mathrm{~mm}$ (1975-2017). The air temperatures in the eight evaluated years were mostly higher than the long-term average (the warmest year was 2014 with $8.3^{\circ} \mathrm{C}$ ); only in 2010 and 2013 the air temperatures were slightly lower than average. The average annual precipitation in a given period was $815 \mathrm{~mm}$, which was also lower than the long-term average. The wettest year in the period under evaluation was 2016, and the driest year was 2015 (which was the driest year observed since 1975).

\section{Radiation balance}

Seasonal and daily values of the radiation balance and its components are presented in Figure 3. Shortwave (SW) radiation generally reaches positive values during the daytime, and approaches zero at night (Fig. 3a)). The mean daily value of incoming SW radiation was $13.6 \mathrm{MJ} \mathrm{m}^{-2} \mathrm{~d}^{-1}$ and outgoing SW radiation was $2.6 \mathrm{MJ} \mathrm{m}^{-2} \mathrm{~d}^{-1}$ (during the period April-October). The long-term average observed ratio of reflected SW radiation to incoming radiation (albedo) over the underlying grass surface was $18.6 \%$. Incoming SW radiation had a strongly seasonal character, with maximum values reaching $28 \mathrm{MJ} \mathrm{m}^{-2} \mathrm{~d}^{-1}$ during the summer season (June-July). No statistically significant trend was detected (using TFPW-MK test) in either incoming or outgoing SW radiation over the 2010-2017 period (at a significance level of 5\%). However, the daily albedo (as the main factor influencing the reflection of radiation) exhibited a significantly decreasing trend during the period of interest, 

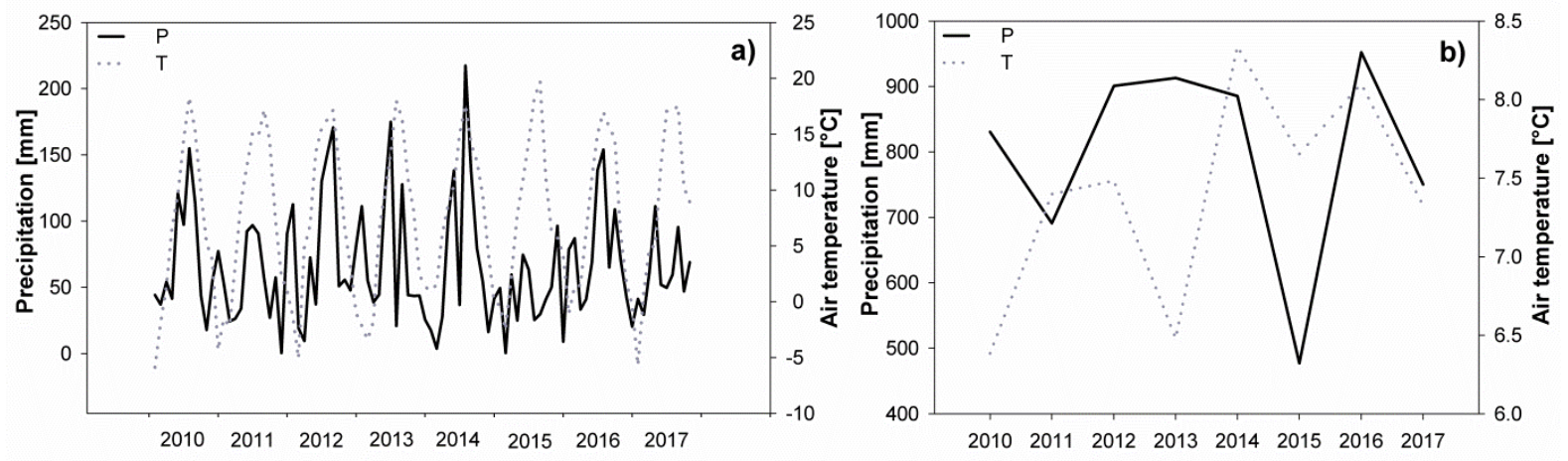

Fig. 2. a) monthly and b) annual climate characteristics of the studied period (January 2010-October 2017).
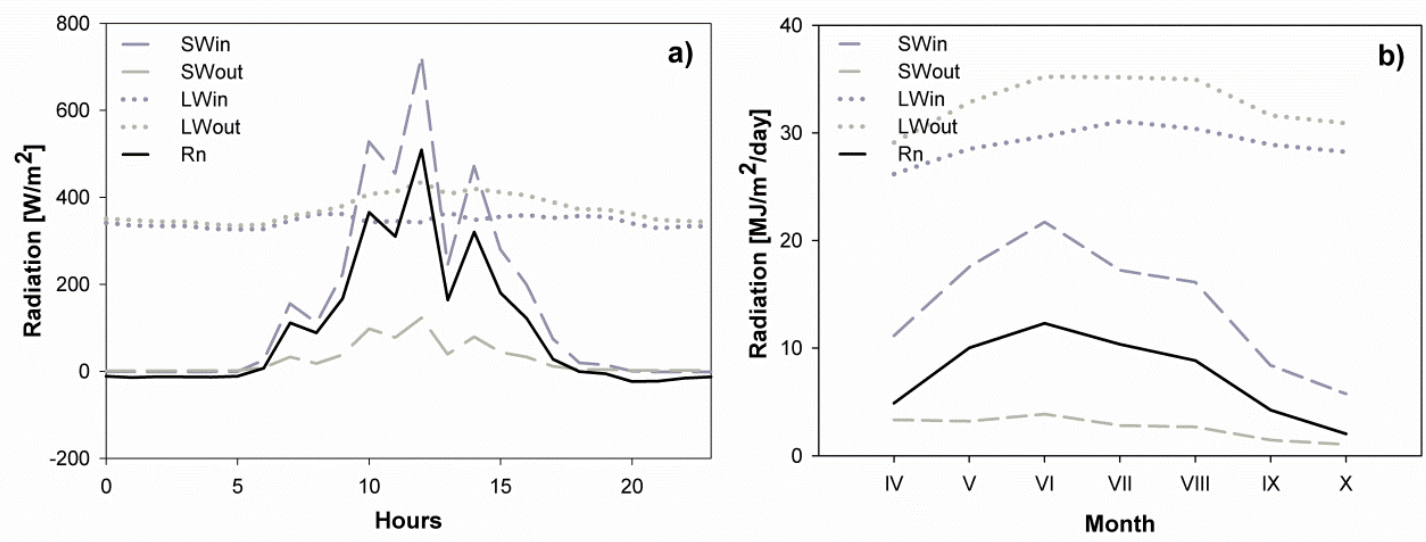

Fig. 3. a) daily (25th April 2014) and b) average seasonal trends in net radiation and its components.

which may be attributable to the long-term evolution of the underlying grass cover.

The observed longwave (LW) radiation exhibited more stable daily and seasonal (annual respectively) patterns (Fig. 3). The mean daily incoming LW radiation was $29.4 \mathrm{MJ} \mathrm{m}^{-2} \mathrm{~d}^{-1}$ and mean daily outgoing LW radiation was $33.0 \mathrm{MJ} \mathrm{m}^{-2} \mathrm{~d}^{-1}$. Altogether, the mean daily net LW radiation (Rnl) was $-3.5 \mathrm{MJ}$ $\mathrm{m}^{-2} \mathrm{~d}^{-1}$. Daily values of Rnl ranged between -9.3 and $0 \mathrm{MJ} \mathrm{m}^{-2}$ $\mathrm{d}^{-1}$. The mean monthly Rnl reached maximum value of $-4.1 \mathrm{MJ}$ $\mathrm{m}^{-2} \mathrm{~d}^{-1}$ in July and a minimum value of $-2.3 \mathrm{MJ} \mathrm{m}^{-2} \mathrm{~d}^{-1}$ in October. The sub-daily pattern of LW radiation was also rather stable (in comparison with SW radiation), with a slight increase in outgoing LW radiation during daylight hours, correlating with an increase in the incoming SW radiation. The variation in incoming LW radiation can be linked to the variation in absolute vapour pressure in the air. Similarly to SW radiation, the TFPW-MK test did not reveal any statistically significant trend in LW radiation series over the studied period.

As the sum of the incoming and outgoing SW and LW radiation, Rn typically demonstrates strong seasonal variation, with maximum in summer and minimum in winter (Fig. 3b)). In general, $\mathrm{Rn}$ is positive during the day and negative at night. Maximum monthly averages approached $10 \mathrm{MJ} \mathrm{m}^{-2} \mathrm{~d}^{-1}$ during the summer season (June-July), and in the autumn the values usually decreased to zero. The average daily value in the period April-October was $7.5 \mathrm{MJ} \mathrm{m}^{-2} \mathrm{~d}^{-1}$, with a maximum of $16 \mathrm{MJ}$ $\mathrm{m}^{-2} \mathrm{~d}^{-1}$. With respect to the separate contributions of SW and LW radiation, the outgoing LW radiation reduces the amount of energy from the incoming SW radiation by $31 \%$ on average. No statistically significant trends were observed in daily $\mathrm{Rn}$ values in the period 2010-2017.

\section{Estimated net longwave radiation (Rnl)}

Rnl was estimated using the FAO56 (RnlFAO56) and FAO24 (RnlFAO24) approaches. Average values of error statistics (compared to observed values) are presented in Figure 4. These results show that $\mathrm{Rnl}_{\mathrm{FAO} 24}$ performed better than RnlFAO56 in comparison with the measured values. The RnlFAO56 method had a strong tendency to underestimate the rate of Rnl; that is, the estimated Rnl was less negative than the observed value. Average BIAS values ranged from 1 to $1.5 \mathrm{MJ} \mathrm{m}^{-2} \mathrm{~d}^{-1}$ for the $\mathrm{Rnl}_{\text {FAO56 }}$ method, while its maximum value was only $0.5 \mathrm{MJ}$ $\mathrm{m}^{-2} \mathrm{~d}^{-1}$ in the case of $\mathrm{Rnl}_{\mathrm{FAO} 24}$ (Fig.4c)). Average annual RMSE values were always higher than $1.4 \mathrm{MJ} \mathrm{m}^{-2} \mathrm{~d}^{-1}$ when using the $\mathrm{Rnl}_{\mathrm{FAO} 56}$ approach, but ranged between 1.0 and 1.25 in the case of FAO24 (Fig.4a)). The RnlFAO56 method produced the highest differences from measured Rnl in 2010, 2016 and 2017. Analyses of monthly averages did not show any seasonal trend in the dissimilarities between measured and modelled Rnl data.

Further, all coefficients included in the RnlFaO56 and RnlFAO24 methods were calibrated. This parameter calibration was preceded by sensitivity analyses (results not shown). The values of chosen objective function (RMSE) were shown to be relatively insensitive to changes in some input coefficients values and thus the calibration of all parameters was not necessary. The least sensitive parameters were $c_{1}$ and $c_{2}$, so their values were kept at the default recommended values $\left(c_{1}=0.75\right.$ and $\left.c_{2}=0.00002\right)$.

The reason for the calibration procedure was to investigate whether it was possible to introduce site-specific values of parameters in order to give a more efficient estimation of Rnl. Initially, all years were first calibrated separately, and different coefficients for each year were determined. Altogether, three 

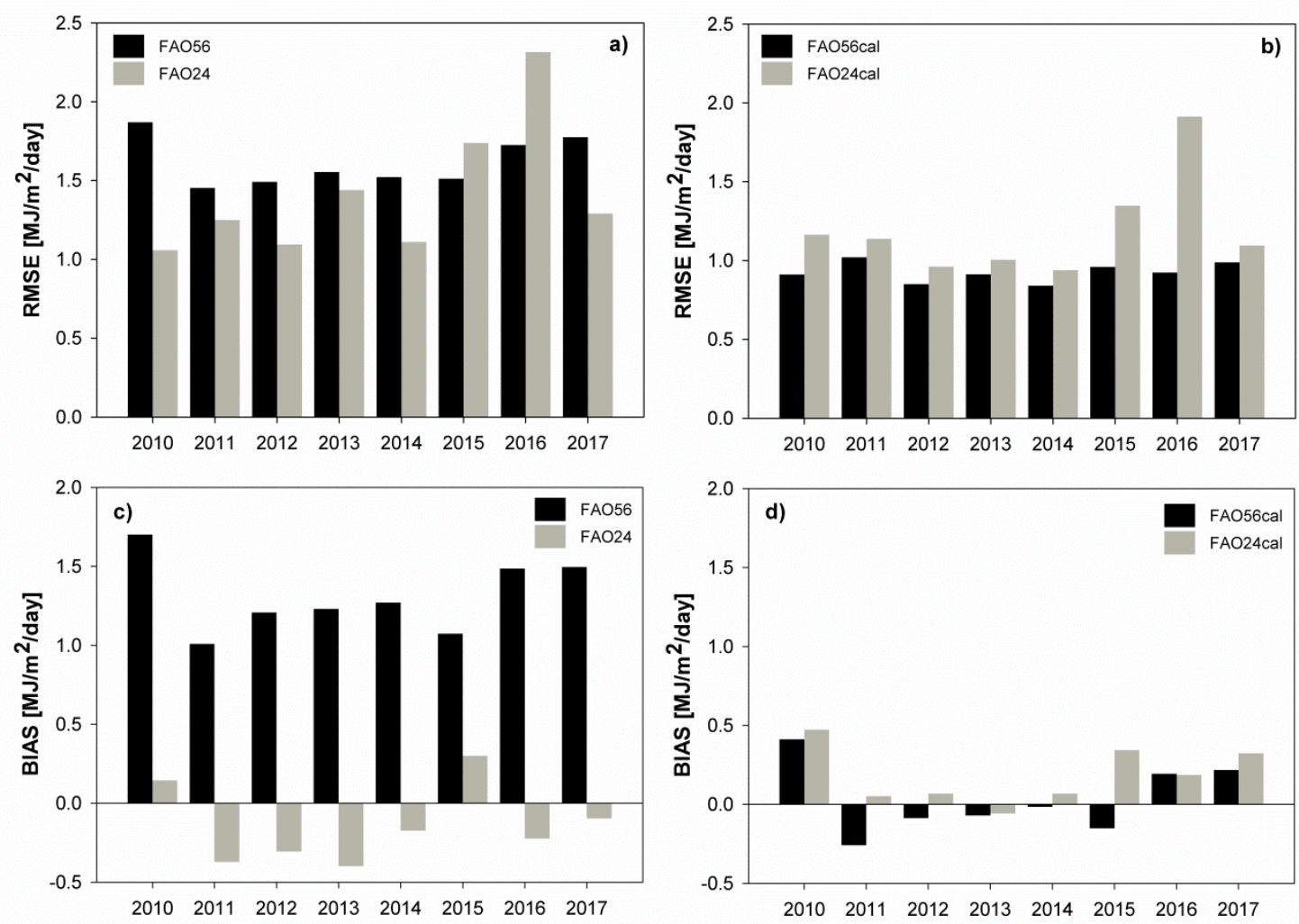

Fig. 4. Error statistics of average daily Rnl modelled using a) FAO56 and c) FAO24 against measured values with default parameter values and b) FAO56 and d) FAO24 after overall calibration.

coefficients were simultaneously calibrated ( $a_{1}$ and $a_{2}$, which express atmospheric emissivity, and $b_{1}$ from the cloudiness factor). The parameter $b_{2}$ was taken as a complement of $b_{1}$ to 1 , as proposed by Allen et al. (1994). For the whole period of eight years, three different sets of coefficients were evaluated (Table 1). The first of these were based on the default parameter values (obtained from the literature); the second were calibrated for each year separately (in order to obtain the best possible model efficiency); and the last originated from the overall calibration (i.e. for the entire period 2010-2017). The resulting parameter values are given in Table 2 for RnlFAO56 and in Table 3 for RnlFaO24. As mentioned in the previous section, Rnl calculated using the RnlFaO56 approach differed notably from the measured values. However, this inconsistency was effectively improved by the coefficient calibration (Table 1). RMSE decreased approximately by $50 \%$ on average and BIAS merely diminished. In case of $\mathrm{Rnl}_{\mathrm{FAO} 24}$ there were no distinct changes (the RMSE decreased by $15 \%$ on average and BIAS remained very low), which can be attributed to the very satisfactory match between the observed and calculated Rnl using default RnlFAO24 parameter values (Fig. 4). The use of overall calibrated coefficient values (instead of the season-specific calibration) did bring only a very little deterioration of error statistics in both RnlFaO56 and RnlFaO24 estimation methods (Table 1). Therefore the use of the single coefficient values for the entire period was justified. However, Figure 5 demonstrates a significant deficiency of the Rnl $l_{\mathrm{FAO} 24}$ approach, which is represented by a less linear relation between the modelled and observed Rnl values. The values are more widely scattered around the 1:1 line than for $\mathrm{Rnl}_{\mathrm{FAO} 56}$, despite representing a better average (reflected by more satisfactory RMSE and BIAS statistics). Although the Rnl FAO56 $_{6}$ generally corresponds better to the distribution of observations, the absolute values were more biased using the default parameter values. Hence, after the calibration of coefficients, RnlFAO56 represents a more plausible approach.

Table 1. Comparison of values of error statistics $\left[\mathrm{MJ} \mathrm{m}^{-2} \mathrm{~d}^{-1}\right]$ before and after calibration of coefficients for Rnl $l_{\mathrm{FAO} 6}$ and Rnl $\mathrm{FAO}_{\mathrm{F} 4}$.

\begin{tabular}{|c|c|c|c|c|c|c|c|c|c|c|c|c|}
\hline & \multicolumn{4}{|c|}{ Default parameter values } & \multicolumn{4}{|c|}{ Calibrated for each year } & \multicolumn{4}{|c|}{ Overall calibration } \\
\hline & \multicolumn{2}{|c|}{ RMSE } & \multicolumn{2}{|c|}{ BIAS } & \multicolumn{2}{|c|}{ RMSE } & \multicolumn{2}{|c|}{ BIAS } & \multicolumn{2}{|c|}{ RMSE } & \multicolumn{2}{|c|}{ BIAS } \\
\hline & FAO56 & FAO24 & FAO56 & FAO24 & FAO56 & FAO24 & FAO56 & FAO24 & FAO56 & FAO24 & FAO56 & FAO24 \\
\hline 2010 & 1.87 & 1.06 & 1.70 & 0.14 & 0.88 & 0.97 & 0.02 & 0.05 & 0.91 & 1.16 & 0.41 & 0.47 \\
\hline 2011 & 1.45 & 1.25 & 1.01 & -0.37 & 0.99 & 1.12 & -0.20 & 0.06 & 1.02 & 1.14 & -0.26 & 0.05 \\
\hline 2012 & 1.49 & 1.09 & 1.21 & -0.31 & 0.86 & 0.95 & -0.34 & 0.08 & 0.85 & 0.96 & -0.09 & 0.07 \\
\hline 2013 & 1.55 & 1.44 & 1.23 & -0.40 & 0.93 & 0.99 & 0.98 & -0.09 & 0.91 & 1.00 & -0.07 & -0.06 \\
\hline 2014 & 1.52 & 1.11 & 1.27 & -0.17 & 0.85 & 0.93 & 0.57 & 0.07 & 0.84 & 0.94 & -0.01 & 0.07 \\
\hline 2015 & 1.51 & 1.74 & 1.07 & 0.30 & 0.95 & 1.31 & 0.27 & -0.05 & 0.96 & 1.35 & -0.15 & 0.34 \\
\hline 2016 & 1.73 & 2.31 & 1.49 & -0.22 & 0.87 & 1.87 & 0.13 & 0.08 & 0.92 & 1.91 & 0.19 & 0.19 \\
\hline 2017 & 1.77 & 1.29 & 1.49 & -0.10 & 0.96 & 1.09 & 0.28 & 0.40 & 0.99 & 1.09 & 0.22 & 0.32 \\
\hline 2010-2017 & 1.61 & 1.39 & 1.20 & -0.11 & 0.91 & 1.20 & 0.21 & 0.04 & 0.93 & 1.19 & 0.03 & -0.03 \\
\hline
\end{tabular}


The influence of observed and modelled net longwave radiation on the rate of estimated potential evapotranspiration

Table 2. Different sets of coefficients for RnlFaO56.

\begin{tabular}{|c|c|c|c|c|c|c|c|c|c|c|}
\hline FAO56 & original & 2010 & 2011 & 2012 & 2013 & 2014 & 2015 & 2016 & 2017 & $2010-2017$ \\
\hline a1 & 0.34 & 0.34 & 0.32 & 0.35 & 0.33 & 0.325 & 0.315 & 0.35 & 0.35 & 0.3 \\
\hline $\mathrm{a} 2$ & -0.14 & -0.1 & -0.1 & -0.12 & -0.101 & -0.1 & -0.1 & -0.1 & -0.1 & -0.1 \\
\hline b1 & 1.35 & 1.12 & 1.12 & 1.13 & 1.15 & 1.09 & 1.05 & 1.1 & 1.1 & 1.08 \\
\hline b2 & -0.35 & -0.12 & -0.12 & -0.13 & -0.15 & -0.09 & -0.05 & -0.1 & -0.1 & -0.08 \\
\hline $\mathrm{c} 1$ & 0.75 & 0.75 & 0.75 & 0.75 & 0.75 & 0.75 & 0.75 & 0.75 & 0.75 & 0.75 \\
\hline $\mathrm{c} 2$ & 0.00002 & $2 \mathrm{E}-05$ & $2 \mathrm{E}-05$ & $2 \mathrm{E}-05$ & $2 \mathrm{E}-05$ & $2 \mathrm{E}-05$ & $2 \mathrm{E}-05$ & $2 \mathrm{E}-05$ & $2 \mathrm{E}-05$ & 0.00002 \\
\hline
\end{tabular}

Table 3. Different sets of coefficients for RnlFaO24.

\begin{tabular}{|c|c|c|c|c|c|c|c|c|c|c|}
\hline FAO24 & original & 2010 & 2011 & 2012 & 2013 & 2014 & 2015 & 2016 & 2017 & $2010-2017$ \\
\hline al & 0.34 & 0.31 & 0.33 & 0.33 & 0.33 & 0.33 & 0.33 & 0.3 & 0.33 & 0.33 \\
\hline a2 & 0.044 & 0.05 & 0.11 & 0.11 & 0.11 & 0.11 & 0.1 & 0.11 & 0.1 & 0.113 \\
\hline b1 & 0.1 & 0.2 & 0.25 & 0.25 & 0.26 & 0.255 & 0.3 & 0.4 & 0.2 & 0.265 \\
\hline $\mathrm{b} 2$ & 0.9 & 0.8 & 0.75 & 0.75 & 0.74 & 0.745 & 0.7 & 0.6 & 0.8 & 0.735 \\
\hline
\end{tabular}
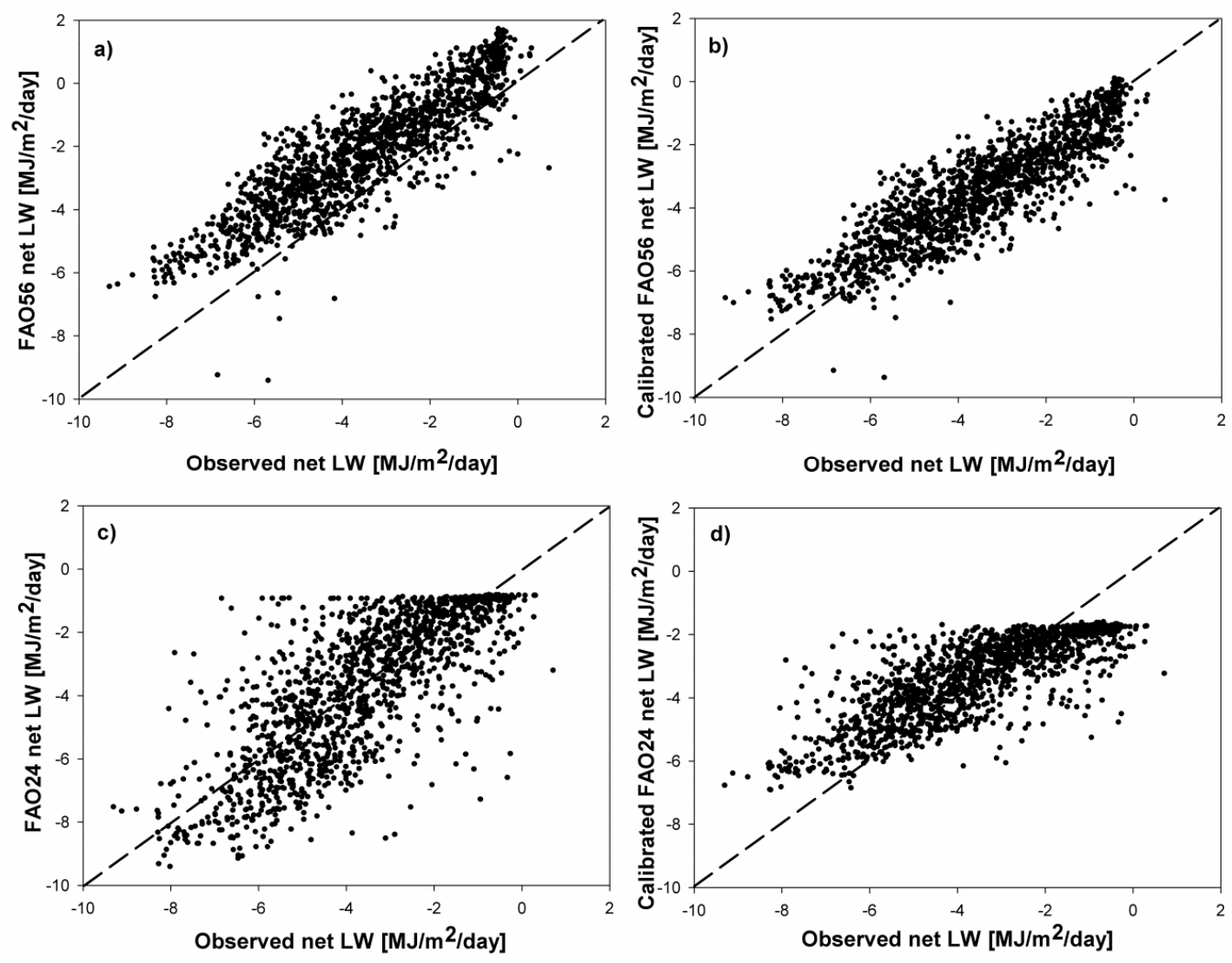

Fig. 5. Relationship between the observed and estimated daily net LW (RnlFAO56 and RnlFAO24), a) and c) before calibration and b) and d) after overall calibration of coefficients.

\section{Influence of the chosen Rnl method on PET estimation}

Potential evapotranspiration was estimated using the combined method of Penman-Monteith (Monteith, 1965). The influence of the measured and estimated Rnl values in the PET equation on the resulting value of evapotranspiration was investigated. The datasets used for estimated Rnl were represented by the values obtained by $\mathrm{Rnl}_{\mathrm{FAO} 56}$ and $\mathrm{Rnl}_{\mathrm{FAO} 24}$ approaches using: (a) default parameter values and (b) a single parameter set arising from the overall calibration. The reference PET (obtained using the measured $\mathrm{Rnl}$ ) ranged from $270 \mathrm{~mm}$ to 433 $\mathrm{mm}$ over one season (April-October). The average daily values were between 1.9 to $2.2 \mathrm{~mm} /$ day in all inspected seasons (Fig. 6). Maximum daily values occurred during summer (June-
July). When using Rnl modelled using RnlFaO56 and Rnl FAO24 methods, the seasonal PET based on the RnlFAO56 was higher by 40 to $100 \mathrm{~mm}$ per a season, while the values of the differences were only up to $20 \mathrm{~mm}$ for the RnlFaO24 method. The daily average differences were from 0.3 to $0.4 \mathrm{~mm} /$ day for RnlFAO56 method and up to $0.2 \mathrm{~mm} /$ day for RnlFAO24 (Fig. 7b)). The overall calibration of the RnlFAO56 coefficients (last column of Table 2) caused a significant decrease in the differences between the values for PET obtained from the measured and estimated Rnl datasets for all years (except 2010 and 2012). Generally, it resulted in very similar values as those obtained by the $\mathrm{Rnl}_{\mathrm{FAO}}$ method before calibration. The $\mathrm{Rnl}_{\mathrm{FAO} 24}$ results showed that overall calibration was not necessary. It even resulted in poorer PET estimation in majority of years when the differences in 

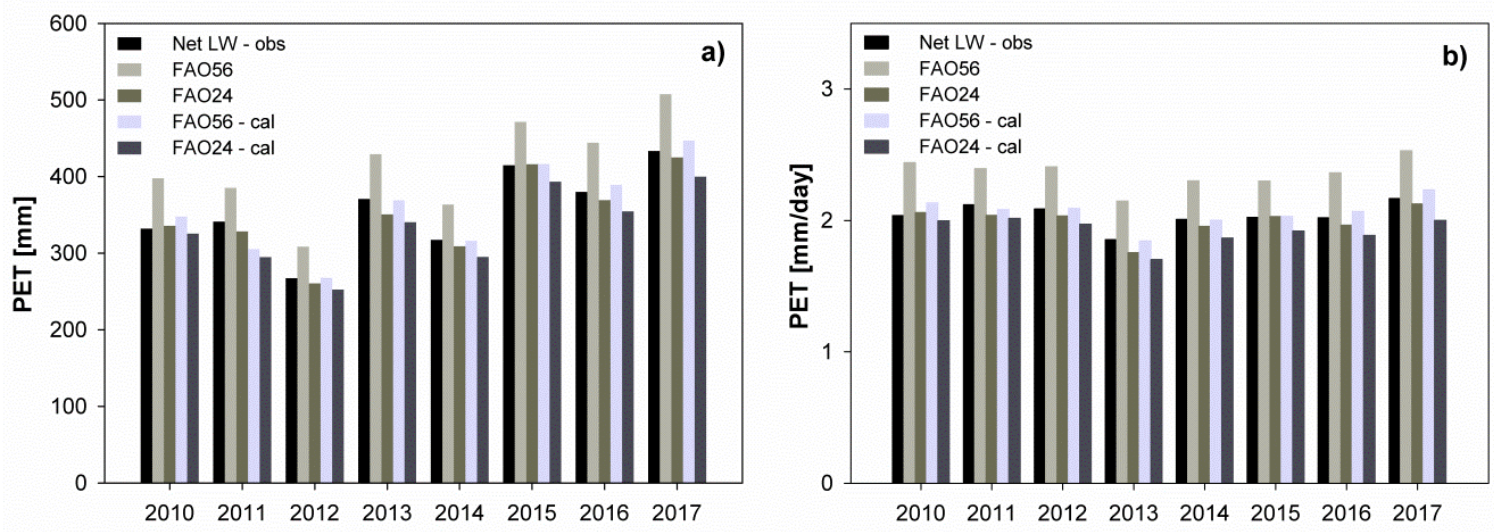

Fig. 6. Estimated a) seasonal and b) daily PET in all years of studied period using Penman-Monteith model.
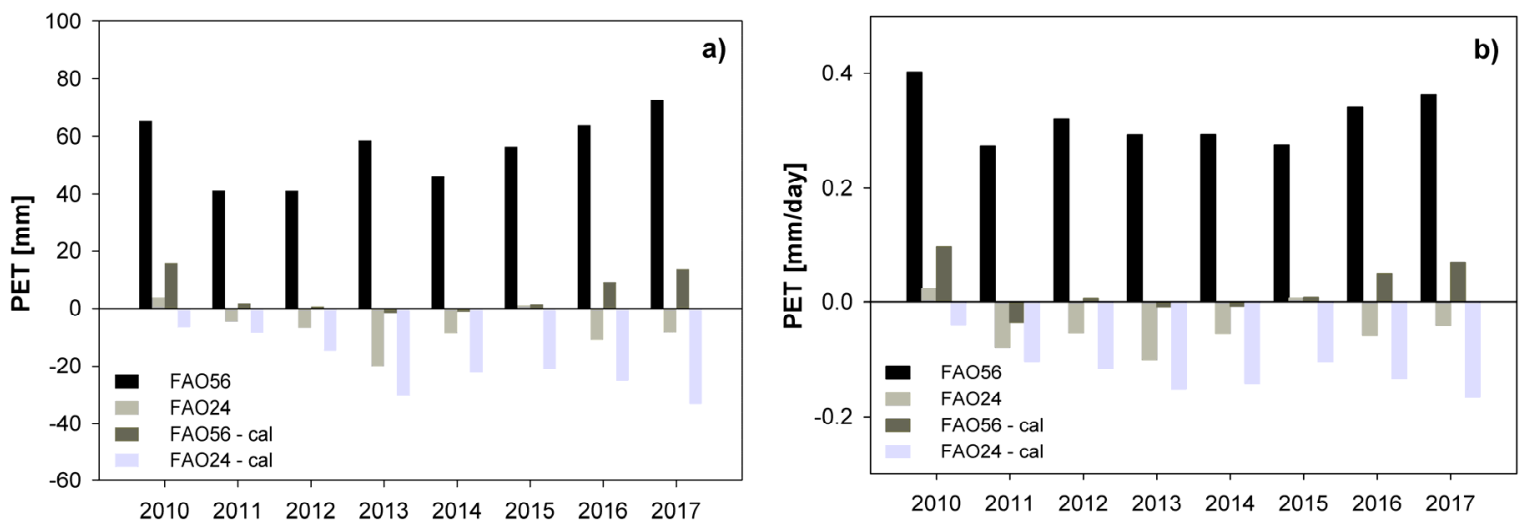

Fig. 7. Absolute differences in PET between the reference PET and those obtained by RnlFaO56/RnlFaO24 (default sets of coefficients) and RnlFaO56-cal/ RnlFAO24-cal (overall calibration), using Penman-Monteith estimation method: a) in seasonal values; b) in daily average values.

PET regularly exceeded $20 \mathrm{~mm}$ per a season or $0.2 \mathrm{~mm} /$ day (Fig. 7). The distribution of the differences in PET values (calculated vs. measured Rnl) over the season was uniform, and no statistically significant trend was identified.

\section{DISCUSSION}

The influence of net longwave radiation estimation approach on the determination of PET was examined. Longwave radiation was continuously measured between 2009 and 2017. These measurements were not taken during the winter months, as snow cover on the radiation sensors would have influenced the measurements. Hence, a different number of days in each year were analysed (since the measurements did not start and end on specific dates each year, but were dictated by presence of snow cover). No inter-seasonal comparison could therefore be carried out due to the different measurement periods used in each year. Despite this factor, the uniqueness of this study lies in the length of the measurement period. Some previous studies focusing on the estimation of Rnl were restricted to shorter time periods, e.g. one (Yin et al., 2008) or three years (Carmona et al., 2017).

In the present study, the default configuration of the RnlFAO56 method has a strong tendency to overestimate Rnl and hence PET in each year examined. Confirming the results of this study, Carmona et al. (2017) also reported overestimation of RnlFAO56 approach in the temperate and sub-humid climate regime of Tandil (Argentina). Conversely, the Rnl was somewhat underestimated in other locations (Matsui and Osawa, 2015; Yin et al., 2008). This can be explained by the non-reference conditions that are likely to be present at every location except the ones were the coefficients were derived. The reason can lie in different influence of the surface characteristics (vegetation type and age), trees and buildings in the surroundings or different presence of small particles and $\mathrm{CO}_{2}$ in the atmosphere. All these factors can influence the longwave radiation balance.

As a result, many researchers have agreed that the calibration of coefficients (expressing the cloudiness factor and atmospheric emissivity) should be carried out based on local conditions (Allen et al., 1998; Carmona et al., 2014; Jensen et al., 1990; Kjaersgaard et al., 2007b, 2009; Matsui and Osawa, 2015; Müller et al., 2014; Yin et al., 2008). The calibration of $\mathrm{Rnl}_{\mathrm{FAO56}}$ coefficients can give rise to a significant improvement compared to measured radiation values (e.g. Matsui and Osawa, 2015). Carmona et al. (2014) found that the coefficients proposed by Allen et al. (1998) provided the highest values of errors in the results. However, after local calibration or when using the coefficients proposed by Jensen et al. (1990) (specifically for humid areas), the RMSE was reduced from around $28 \%$ to $-1+15 \%$. The outcomes of this study are in agreement with this improved performance of the RnlFAO56 method after calibration. 
The RnlFaO24 performed better than RnlFaO56 over the entire study period, and the calibration of coefficients enhanced the results only to a limited extent. However, this concerned only the average error statistics and the distribution of daily values RnlFAO24 was notably biased when compared to the measured ones (Fig. 5). As the distribution of RnlFaO24 was limited by the value of $-0.9 \mathrm{MJ} \mathrm{m}^{-2} \mathrm{~d}^{-1}$, which is conditioned by a zero duration of sunshine on any given day. On these days, low values of $\mathrm{SW}$ radiation (embedded in the RnlFAO56 cloudiness correction) can be still observed, and the Rnl $\mathrm{FAO}_{6}$ therefore enables a more accurate estimation of low Rnl values. The limit is undermined by the limited amount of water vapour that can be held in the air at certain air temperature (saturation vapour pressure). There is no comparable evidence from the use of this method in other locations and climate conditions.

Standard Penman-Monteith equation was chosen for the estimation of PET. Since Rn is one of the variables used in this approach, the use of $\mathrm{Rnl}_{\mathrm{FAO} 56}$ and $\mathrm{Rnl}_{\mathrm{FAO} 24}$ modelling proved to have the effect on PET calculation (Detlefsen and Plauborg, 2001, in Kjaersgaard et al., 2007b). Estimated PET was usually overestimated in the period under study when using the RnlFa056 approach. A similar effect was observed by Yin et al. (2008), who found overestimations of up to $27 \%$. On the other hand, $\mathrm{Rnl}_{\mathrm{FAO} 24}$ tended to underestimate the PET results in all years (except for 2010). Calibration of coefficients improved the PET results in the entire period. Three additional PET estimation methods (Pristley and Taylor method, 1972, KimberlyPenman method, Wright, 1982 and Thom and Oliver method, 1977) were examined in a side-experiment in order to observe the sensitivity of results. The types and magnitudes of the errors were very similar in all of the utilised PET estimation methods. This was given by the fact that all the chosen methods are simplified versions of the original Penman-Monteith equation. In general, the calibration of coefficients based on local conditions gave more accurate PET estimates (compared to the use their default values). This is of significant importance for the modelling practice as it can reduce the uncertainty in the estimation of the PET rate, which is one of the two key factors determining the amount of actual evapotranspiration (AET). The inaccurately estimated AET inevitably leads to inaccurate water balance equation components estimation, although the model performance (based on error statistics) could be satisfactory (Šípek and Tesař, 2017).

While the $\mathrm{Rnl}_{\mathrm{FAO} 56}$ approach is widely used in modelling practice (e.g. Kjaersgaard et al., 2009), Rnl FAO24 $_{4}$ is rarely used (due to a lack of information on the actual sunshine duration). The accuracy of both modelling approaches without parameter calibration (coefficients describing atmospheric and cloud conditions) is questionable, as it can vary for different locations and climate conditions. In this study, the default RnlFAO24 generally performed better, but only when observing average error statistics. The distribution of daily values was more variable

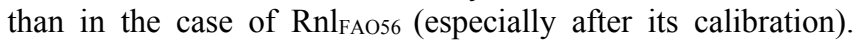
Hence, the modelling of PET using the estimated Rnl requires a parameter calibration that reflects the site-specific conditions (Allen et al., 1998; Jensen et al., 1990).

\section{SUMMARY AND CONCLUSIONS}

Potential evapotranspiration by Penman-Monteith (Monteith, 1965) method was evaluated at the Liz catchment using the measured net longwave radiation ( $\mathrm{Rnl})$ and results of calculation from the FAO56 (RnlFaO56) and FAO24 (RnlFAO24) Rnl equations. The study showed that RnlFAO56 has a strong tendency to underestimate the values of LW radiation balance while using default set of coefficients. The calibration of coefficients generated significant improvements over the entire studied period (2010-2017) when using RnlFAO56. While RMSE of RnlFaO56 decreased approximately by $50 \%$ on average (and BIAS merely diminished), RnlFAO24 exhibits small or no improvements with values decreasing by $15 \%$ on average in case of RMSE. BIAS remained unaffected by the calibration procedure. Following this calibration, the RnlFAOs6 approach was found to be more reliable, since the distribution of LW radiation values corresponded better to the observed values (in addition to the values of RMSE and BIAS). The distribution of values of LW using Rnl $\mathrm{FAO}_{24}$ approach, which relies on the duration of sunshine, was affected by the fact that some SW radiation is observed even when no sunshine is recorded. As a result, the estimation of PET using default parameter values in $\mathrm{Rnl}_{\mathrm{FAO}} 56$ method produced seasonal difference of $40-100 \mathrm{~mm}$ from the values estimated based on the measured radiation balance; these differences reached only $20 \mathrm{~mm}$ on average per season in the case of Rnl $\mathrm{FaO}_{24}$ using default coefficients. The errors in PET significantly decreased after calibration (up to 20 $\mathrm{mm}$ per season), and hence the local calibration of coefficients is strongly recommended when using the RnlFaO56 procedure. This proposed approach will lead to more accurate hydrological simulation in terms of water balance equation components estimation.

Acknowledgements. This research was supported by the Czech Science Foundation (GA CR 16-05665S), the institutional support of the Czech Academy of Sciences, Czech Republic (RVO: 67985874), and by the programme framework of the Strategy AV21. Radiation data were available through the courtesy of the Faculty of Civil Engineering, Czech Technical University in Prague.

\section{REFERENCES}

Allen, R.G., Smith, M., Perrier, A., Pereira, L.S., 1994. An update for the definition of reference evapotranspiration. ICID Bulletin, 43, 2, 35-92.

Allen, R.G., Pereira, L.S., Raes, D., Smith, M., 1998. Crop evapotranspiration - Guidelines for computing crop water requirements. FAO Irrigation and Drainage Paper 56, Rome, 300 p.

Arellano, M.G., Irmak, S., 2016. Reference (potential) evapotranspiration. I: Comparison of temperature, radiation, and combination-based energy balance equations in humid, subhumid, arid, semiarid and mediterranean-type climates. Journal of Irrigation and Drainage Engineering, 142, 4, 21 p.

Carmona, F., Rivas, R., Caselles, C., 2014. Estimation of daytime downward longwave radiation under clear and cloudy skies conditions over sub-humid region. Theoretical and Applied Climatology, 115, 281-295.

Carmona, F., Rivas, R., Kruse, E., 2017. Estimating daily net radiation in the FAO Penman-Monteith method. Theoretical and Applied Climatology, 129, 89-95.

Dalton, J., 1802. Experimental essays on the constitution of mixed gases: On the force of steam or vapor from water or other liquids in different temperatures, both in a Torricelli vakuum and in air; on evaporation; and on expansion of gases by heat. Manchester Literary Philosophical Society Mem. Proceedings, 5, 536-602.

Doorenbois, J., Pruitt, W.O., 1977. Guidelines for predicting crop water requirements. FAO Irrigation and Drainage Paper 24, Rome, $179 \mathrm{p}$

Duarte, H.F., Dias, N.L., Maggiotto, S.R., 2006. Assessing daytime downward longwave radiation estimates for clear 
and cloudy skies in Southern Brazil. Agricultural and Forest Meteorology, 139, 171-181.

Fisher, J.B., DeBiase, T.A., Qi, Y., Xu, M., Goldstein, A.H., 2005. Evapotranspiration methods compared on a Sierra Nevada forest ecosystem. Environmental Modelling \& Software, 20, 6, 783-796.

Irmak, S., ASCE, M., Irmak, A., Jones, J.W., Howell, T.A., ASCE, M., Jacobs, J.M., Allen, R.G., ASCE, M., Hoogenboom, G., 2003a. Predicting daily net radiation using minimum climatological data. Journal of Irrigation and Drainage Engineering, 129, 4, 256-269.

Irmak, S., Irmak, A., Allen, R.G., Jones, J.W., 2003b. Solar and net radiation-based equations to estimate reference evapotranspiration in humid climates. Journal of Irrigation and Drainage Engineering, 129, 5, 336-347.

Irmak, S., Mutiibwa, D., Payero, J.O., 2010. Net radiation dynamics: Performance of 20 daily net radiation models as related to model structure and intricacy in two climates. Transactions of the ASABE, 53, 4, 1059-1076.

Jensen, M.E., Burman, R.D., Allen, R.G., 1990. Evapotranspiration and water requirements, ASCE Manual 70, New York, $332 \mathrm{p}$.

Kendall, M.G., 1938. A new measure of rank correlation. Biometrika, 30, 1/2, 81-93.

Kjaersgaard, J.H., Cuenca, R.H., Plauborg, F.L., Hansen, S., 2007a. Long-term comparisons of net radiation calculation schemes. Boundary-Layer Meteorology, 123, 417-431.

Kjaersgaard, J.H., Plauborg, F.L., Hansen, S., 2007b. Comparison of models for calculating daytime long-wave irradiance using long term data set. Agricultural and Forest Meteorology, 143, 49-63.

Kjaersgaard, J.H., Cuenca, R.H., Martínez-Cob, A., Gavilán, P., plauborg, F., Mollerup, M., Hansen, S., 2009. Comparison of the performance of net radiation calculation models. Theoretical and Applied Climatology, 98, 57-66.

Mann, H.B., 1945. Nonparametric tests against trend. Econometrica, 13, 3, 245-259.

Matsui, H., Osawa, K., 2015. Calibration effects of the net longwave radiation equation in Penman-type methods at Tateno, Japan. Hydrological Reseatch Letters, 9, 4, 113-117.

Monteith, J.L., 1965. Evaporation and the environment. The state and movement pf water in living organisms. In: XIX. Symposium of the Society for Experimental Biology, Cambridge University Press, 205-234.

Müller, J., Dohnal, M., Tesař, M., 2014. Testování parametrizací složek dlouhovlnného záření $\mathrm{v}$ podmínkách malého šumavského povodí. In: Hydrologie malého povodí 2014. Institute of hydrodynamics CAS, Prague, pp. 329-334.

Penman, H.L., 1948. Natural evaporation from open water, bare soil and grass. Proceedings of the Royal Society of London. Series A, Mathematical and Physical Sciences, 193, 120145.

Pianosi, F., Beven, K., Freer, J., Hall, J.W., Rougier, J., Stephenson, D.B., Wagener, T., 2016. Sensitivity analyses of environmental models: A systematic review with practical workflow. Environmental Modelling \& Sofware, 79, 214232.

Pristley, C.H.B., Taylor, R.J., 1972. On the assessment of surface heat fluxes and evaporation using large-scale parameters. Monthly Weather Review, 100, 81-92.

Shi, T., Guan, D., Wang, A., Wu, J., Jin, C., Han, S., 2008. Comparison of three models to estimate evapotranspiration for a temperate mixed forest. Hydrological Processes, 22, 3431-3443.

Šípek, V., Tesar̆, M., 2017. Year-round estimation of soil moisture content using temporally variable soil hydraulic parameters. Hydrological Processes, 31, 1438-1452.

Temesgen, B., Eching, S., ASCE, M., Frame, K., 2007. Comparing Net Radiation Estimation Methods: CIMIS versus Penman-Monteith. Journal of Irrigation and Drainage Engineering, 133, 265-271.

Thom, A.S., Oliver, H.R., 1977. On Penman's equation for estimating regional evaporation. Quarterly Journal of the Royal Meteorological Society, 103, 345-357.

Votrubová, J., Dohnal, M., Vogel, T., Šanda, M., Tesař, M., 2017. Episodic runoff generation at Central European headwater catchments studied using water isotope concentration signals. Journal of Hydrology and Hydromechanics, 65, 2, 114-122.

Wright, J.L., 1982. New evapotranspiration crop coefficients. Journal of Irrigation and Drainage Engineering, 108, 1, 5774.

Yin, Y., Wu, S., Zheng, D., Yang, Q., 2008. Radiation calibration of FAO56 Penman-Monteith model to estimate reference crop evapotranspiration in China. Agricultural Water Management, 95, 77-84.

Yue, S., Pilon, P., Phinney, B., Cavadias, G., 2002. The influence of autocorrelation on the ability to detect trend in hydrological series. Hydrological Processes, 16, 1807-1829.

Received 11 September 2018 Accepted 18 January 2019 